\title{
Technologia lutowania twardego prętów uzwojenia stojana turbogeneratora
}

\author{
Brazing technology \\ of turbogenerator stator winding bars
}

\section{Streszczenie}

Lutowanie prętów stojana ze skuwką, z dużą liczbą miedzianych przewodów elementarnych, jest procesem specjalnym, wynikającym ze złożonej konstrukcji lutowanego złącza. W opracowanej technologii lutowania twardego zastosowano regulowany docisk górny pakietu, zmieniany przed rozpoczęciem procesu i bezpośrednio przed jego zakończeniem. Wywierany jest on przez siłowniki hydrauliczne, co umożliwia ciągłą kontrolę docisku oraz nadzorowanie parametrów procesu w trakcie jego trwania. Ponadto zastosowano precyzyjne dozowanie wymaganej ilości lutu, deponowanego w konkretnych miejscach podczas montażu skuwki, przed procesem lutowania.

Słowa kluczowe: przewody miedziane; beztopnikowe lutowanie indukcyjne; połączenia lutowane; wypełnienie szczelin lutowniczych; tomografia komputerowa; badania metalograficzne; statyczna próba ścinania

\begin{abstract}
Brazing of the stator bar lugs with a high number of individual copper strands is a special process due to complex design of the brazed joint. The new brazing technology applied utilizes adjustable pressure from the top, varied of the lug prior to heating and directly before end of the brazing procedure. The pressure is exerted by a hydraulic device enabling measurement of the process parameters and control the process. Additionally it was precisely dosed amount of bearing braze metal deposited in certain places during the lug assembly, before the brazing process.
\end{abstract}

Keywords: copper strands; induction brazing without flux; brazing joint; filling between the strands; thomography; metallographic examination; static shear strength test

\section{Wstęp}

Indukcyjne lutowanie twarde miedzianych skuwek z miedzianymi przewodami elementarnymi prętów generatora w całość, należy do podstawowych technologii wytwarzania uzwojenia stojana i stanowi zadanie niezmiernie trudne z uwagi na wyjątkowo złożony układ lutowania. Konstrukcja lutowana zawiera przynajmniej dwie kolumny, w każdej z nich jest ponad 60 miedzianych przewodów elementarnych, skuwkę i nakładkę [1]. Omawiana technologia lutowania twardego dotyczy generatorów dużej mocy (rys. 1 i 2).

$\mathrm{Na}$ rysunku 2 można zauważyć, że złącze lutowane (skuwka) składa się z dwóch stosów elementarnych przewodów miedzianych (nazywanych kolumnami), skuwki w kształcie L-profilu i bocznej nakładki.
Dotychczas proces lutowania prowadzono ręcznie na stanowiskach produkcyjnych przy użyciu prostego oprzyrządowania, złożonego z docisków ręcznych. Proces lutowania jest/był opisany instrukcją BPS, a każdy pracownik wykonujący proces powinien posiadać ważne uprawnienia lutowacza (zgodnie z PN - EN ISO 13585: 2012 [2]) potwierdzone przez jednostkę certyfikującą. Dlatego też, dużą rolę w jakości połączenia odgrywały predyspozycje i doświadczenie pracowników.

Kryterium oceny prawidłowości połączenia stanowią wymagania normy PN - EN ISO 18279: 2008 [3], które określają stopień wypełnienia $\mathrm{w}$ złączu na poziomie przynajmniej $80 \%$.

Prof. dr hab. inż. Zbigniew Mirski; prof. dr hab. inż. Edward Chlebus; dr hab. inż. Kazimierz Granat, prof. nzw. PWr; dr inż Grzegorz Ziółkowski - Politechnika Wrocławskia; dr inż. Tomasz Krause; mgr inż. Konrad Lickiewicz; mgr inż. Arkadiusz Toporczyk - General Electric Power Sp. z o.o. w Warszawie, Oddział we Wrocławiu; mgr inż. Kurt Steigleder - GE Power Baden (Szwajcaria).

Autor korespondencyjny/Corresponding author: zbigniew.mirski@pwr.edu.pl 


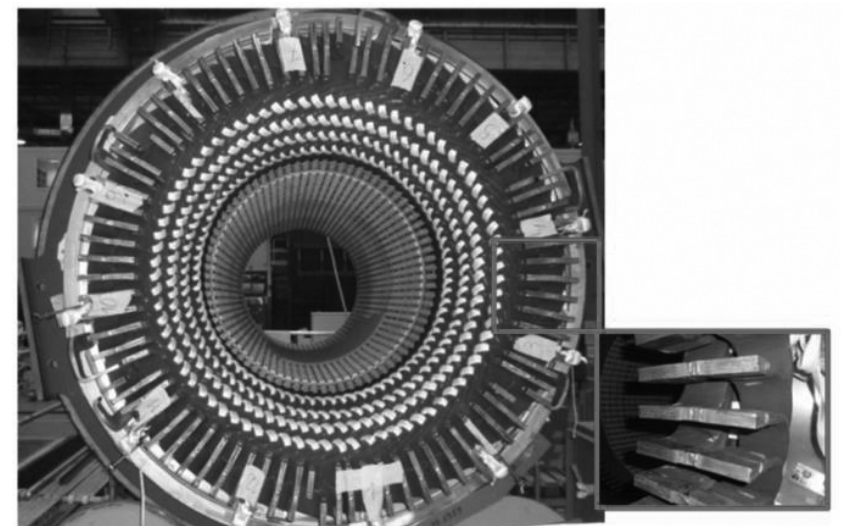

Rys. 1. Stojan generatora o mocy ok. 300 MVA, po prawej stronie szczegół dotyczący lutowanych prętów uzwojenia stojana ze skuwką Fig. 1. Generator, power range approximately 300MVA, on the right hand side the item related to brazing of the stator bar lug

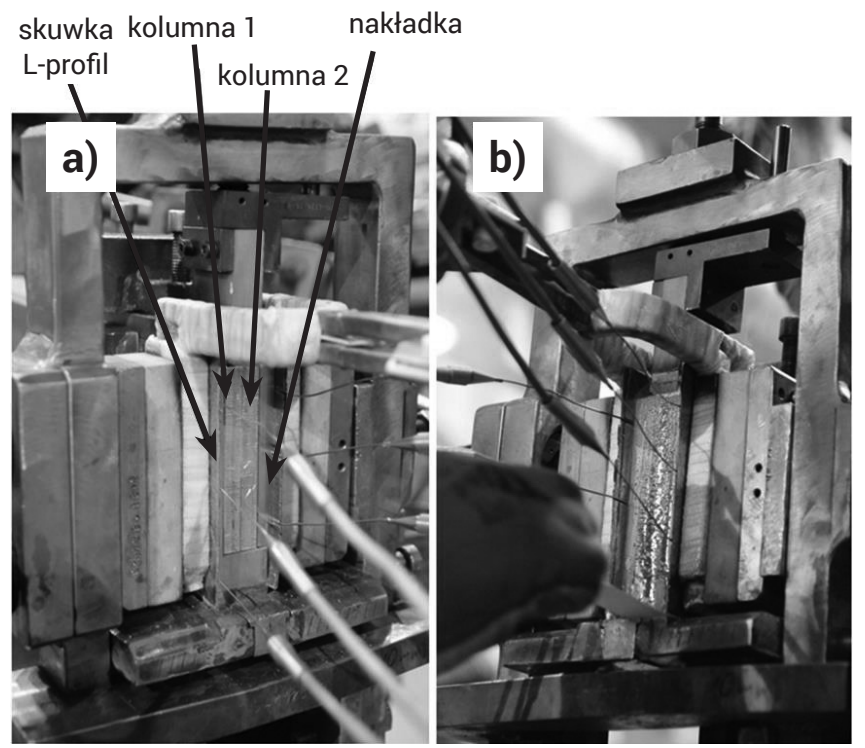

Rys. 2. Widok: przed (a) i podczas (b) procesu lutowania indukcyjnego skuwki z równoczesnym pomiarem temperatury lutowania

Fig. 2. View: before (a) and during (b) of the induction brazing of the lug with the simultaneous measurement of brazing temperature

W związku z tym, w pierwszym etapie opracowania technologii wykonywane były złącza próbne i sprawdzane było wypełnienie szczeliny lutowniczej pomiędzy każdym indywidualnym przewodem miedzianym, ponieważ tak oceniane jest pojedyncze złącze pręta generatora. Wcześniej, przed opracowaną nową technologią lutowania skuwek, w warunkach produkcyjnych, w celu kontroli wymaganej jakości procesu lutowania, każdy pręt uzwojenia stojana był badany metodą ultradźwiękową.

Podczas opracowywania nowej technologii indukcyjnego lutowania twardego, prowadzono metalograficzne badania niszczące i kontrolowano jakość połączenia na wyciętych, specjalnie do tego celu przygotowanych, pojedynczych próbkach.

\section{Technologia lutowania}

Opracowując nową technologię lutowania dobrano, po szeregu prób, przeprowadzonych w Alstom Power (obecnie GE Power) we Wrocławiu i badań w Politechnice Wrocławskiej, takie parametry lutowania, które praktycznie doprowadziły do całkowitego wypełnienia szczelin lutowniczych, a tym samym do osiągnięcia bardzo wysokiej jakości połączeń lutowanych prętów uzwojenia stojana [1]. Należało określić i uwzględnić następujące parametry lutowania:

- regulowany docisk górny i boczny skuwki, przed rozpoczęciem nagrzewania i bezpośrednio przed zakończeniem lutowania, poprzez zainstalowanie specjalnie zaprojektowanego i wykonanego układu hydraulicznego, z pomiarem wielkości docisku na manometrach kontrolnych;

- temperaturę lutowania, poprzez pomiary i sterowanie rozkładem ciepła w nagrzewanej i lutowanej skuwce;

- ilość ściśle dozowanego lutu srebrnego z fosforem CuP 284 (w \% wag.: 4,8-5,2 \% P, 14,5-15,5\% Ag, reszta $\mathrm{Cu}$ ), o zakresie temperatury topnienia $645-800{ }^{\circ} \mathrm{C}$, zgodnie z PN - EN ISO 17672: 2010 [4], dobraną doświadczalnie i określić miejsca jego zdeponowania podczas montażu skuwki, przed rozpoczęciem procesu lutowania;

- wprowadzenie drgań mechanicznych o małej częstotliwości do układu lutowania.

Zastosowane sterowanie parametrami lutowania charakteryzuje się pełną, kontrolowaną hydrauliką, dzięki której proces jest powtarzalny. Sprawdzono to poprzez liczne próby lutowania złączy testowych. Wyeliminowano w znacznym stopniu wpływ czynnika ludzkiego na efekty lutowania. Zgodnie z normą PN - EN ISO 18279: 2008 [3], przy najbardziej restrykcyjnych wymaganiach, osiągnięto prawidłowe wypełnienie lutem szczelin pomiędzy każdą parą przewodów elementarnych.

\section{Badania połączeń lutowanych skuwki}

W warunkach produkcyjnych jednoznaczne określenie wypełnienia szczelin lutowniczych za pomocą badań nieniszczących jest niemożliwe. W związku z tym, w celu określenia poprawności technologii lutowania, gotowe złącze lutownicze (skuwka) cięto na 7 części o grubości ok. 3,5 mm i analizowano każdy poprzeczny przekrój (rys. 3). a)

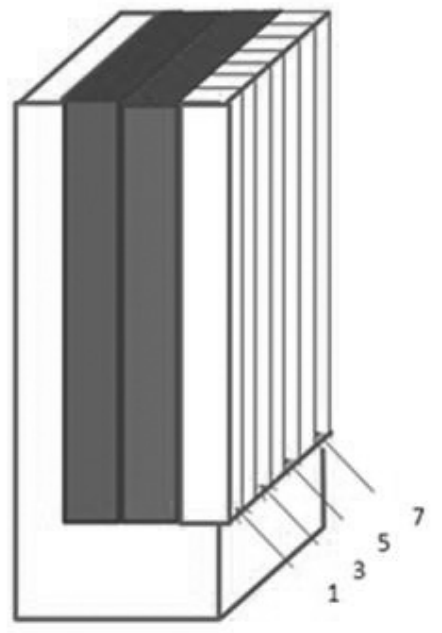

b)

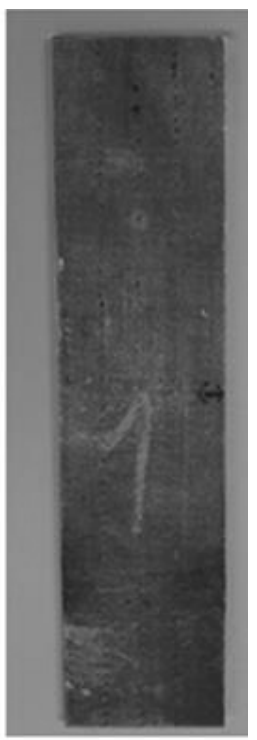

Rys. 3. Szkic przedstawiający metodykę cięcia skuwki (a) i zdjęcie pojedynczej próbki (b)

Fig. 3. Sketch presenting method of the cutting (a) and picture of individual sample (b)

Przygotowane w ten sposób próbki poddawano prześwietlaniu w badaniach tomograficznych, a następnie badaniom metalograficznym mając na celu ocenę stopnia wypełnienia lutem przestrzeni pomiędzy każdym elementarnym przewodem miedzianym.

Wynik badania próbek za pomocą tomografu komputerowego Metrotom 1500 Carl Zeiss o maksymalnym napięciu $225 \mathrm{kV}$, pokazano przykładowo na rysunku 4. 


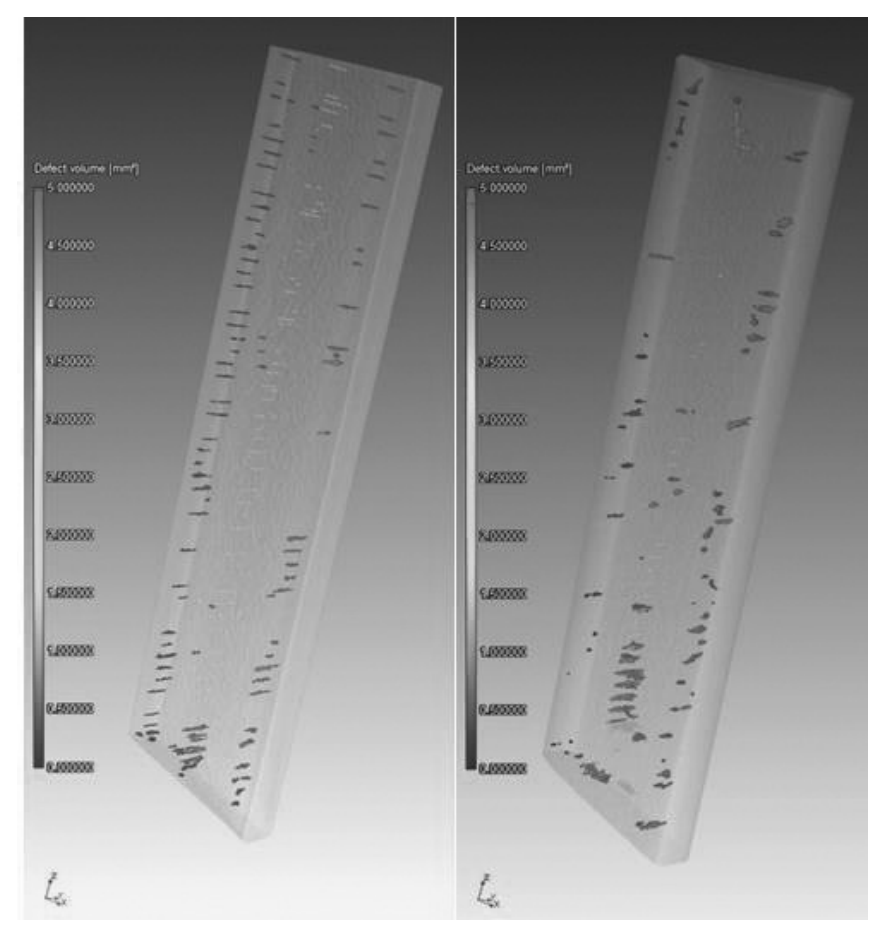

Rys. 4. Porowatość badanych próbek po prześwietleniu tomografem komputerowym

Fig. 4. Porosity of the sample after thomography examination

W wyniku zastosowania nowo opracowanej technologii lutowania stopień wypełnienia szczelin lutowniczych się-

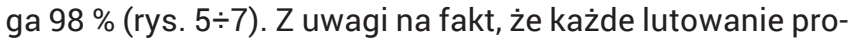
wadzone jest w ten sam sposób, proces jest powtarzalny, zatem nie wymaga się w tym przypadku mało miarodajnej dla takiego przypadku kontroli ultradźwiękowej każdego pręta.

Podczas walidacji procesu lutowania zwrócono uwagę na aspekt stanu przygotowania powierzchni skuwki do lutowania. W każdym przypadku skuwka była zamawiana od producenta $\mathrm{w}$ formie prostopadłościennego pręta, po czym była frezowana na wymiar. Stan chropowatości powierzchni, określony parametrem Ra po obróbce wynosił od 2 do $4 \mu \mathrm{m}$. W związku z tym, że dopuszczalne jest produkowanie i lutowanie skuwek w technologii ciągnionej, a jej chropowatość powierzchni $R a$ jest na poziomie $0,2-0,3 \mu \mathrm{m}$, interesującym aspektem był wpływ chropowatości na jakość lutowania.

W celu określenia wpływu chropowatości powierzchni skuwki na stopień wypełnienia lutem, wykonano 2 złącza
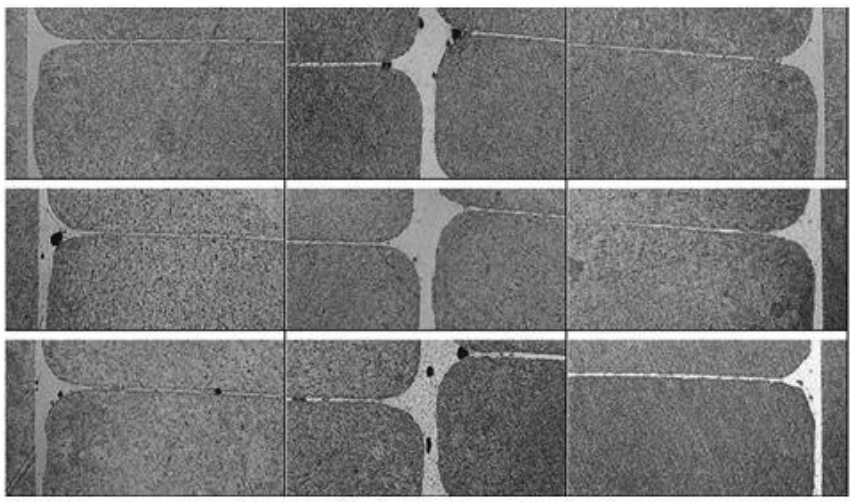

Rys. 5. Makrostruktura połączeń lutowanych wg opracowanej technologii, pełne wypełnienie lutem szczelin poziomych pomiędzy przewodami elementarnymi, grubość przewodów miedzianych 1,5 mm Fig. 5. Macrostructure of brazing joint acc. to new technology, full filling of the gap between individual strands, strand thickness $1.5 \mathrm{~mm}$

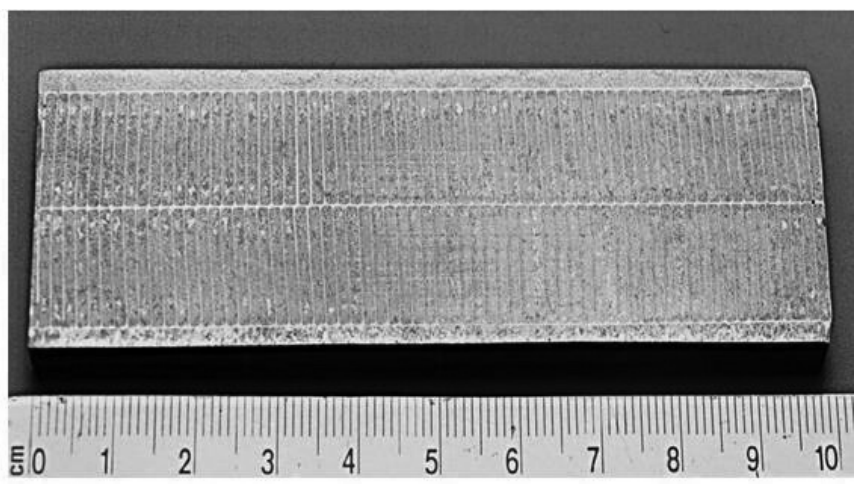

Rys. 6. Przekrój poprzeczny skuwki, polutowanej wg nowej technologii, z pełnym wypełnieniem szczelin

Fig. 6. Cross section of sample brazed acc. to new technology with full filling of the gap between the strands

testowe (skuwki) o różnej chropowatości przygotowania powierzchni, przy powtarzalnej szerokości szczeliny lutowniczej sięgającej do $0,15 \mathrm{~mm}$. Dla powierzchni skuwki o chropowatości $R a$ równej 0,2-0,3 $\mu \mathrm{m}$ uzyskano średnie wypełnienie lutem na poziomie $99 \%$, natomiast w przypadku parametru $R a=2-4 \mu \mathrm{m}$ wypełnienie było nieco mniejsze i wyniosło $96,7 \%$. W obydwu przypadkach wypełnienie lutem spełnia wymagania PN - EN ISO 18279: 2008 [3].
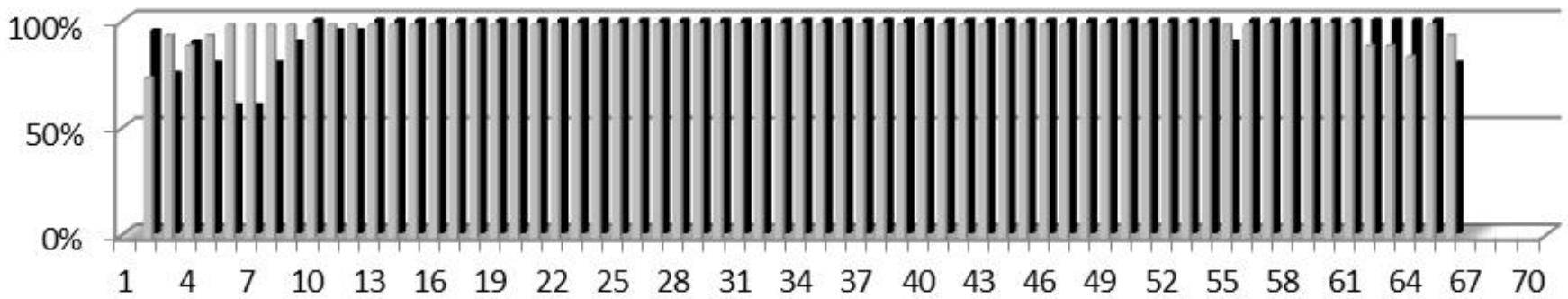

Rys. 7. Wypełnienie lutem między poszczególnymi przewodami miedzianymi, kolor jasny ilustruje wypełnienie pierwszej kolumny (98 \%), natomiast czarny drugiej (97\%)

Fig. 7. Filling with brazing metal between individual strands, bright color illustrates filling with the column 1 (98 \%) and black one in the column $2(97 \%)$ 


\section{Podsumowanie}

Analizując wyniki przeprowadzonych badań należy podkreślić znaczenie, w ocenie jakości złożonych i odpowiedzialnych połączeń lutowanych, odpowiednio dobranych i zastosowanych metod pomiarowych, tj. metodę tomografii komputerowej oraz badania metalograficzne. Klasyczna metoda radiograficzna nie zapewnia uzyskania jednoznacznych wyników, a przez to ogranicza możliwość oceny jakości połączeń lutowanych.

Metodyka realizacji opracowanego sposobu lutowania, połączona z właściwie dobranymi badaniami kontrolnymi pozwoliła na jednoznaczne i czytelne przedstawienie uzyskanych efektów procesu lutowania.

Efektem usprawnionego procesu lutowania jest:

- zapewnienie dobrej jakości lutowanych skuwek miedzianych prętów uzwojenia stojanów generatorów dużej mocy;

- przyspieszenie produkcji, poprzez wyeliminowanie poprawek i znaczne zmniejszenie ilości operacji badań ultradźwiękowych;

- możliwość zredukowania do minimum wpływu czynnika ludzkiego na efekty bardzo odpowiedzialnego procesu lutowania twardego.

Wszystkie wprowadzone czynniki rzutują na jakość, niezawodność i bezpieczeństwo pracy produkowanych generatorów.

\section{Literatura}

[1] Chlebus E., Mirski Z., Granat K., Dybała B., Ziółkowski G.: Quality evaluation of all the brazed lugs - test pieces representing the lugs WT21 $\mathrm{H}-102$ and TOPAIR 23Z-109, Raport serii SPR nr 15/2014, Politechnika Wrocławska, Wrocław 2014.

[2] PN - EN ISO 13585: 2012 Lutowanie twarde. Kwalifikowanie lutowaczy i operatorów lutowania twardego.

[3] PN - EN ISO 18279: 2008 - Lutowanie twarde. Niezgodności w złączach lutowanych na twardo.

[4] EN ISO 17672 2:2010 - Brazing. Filler metals. 